\title{
FORMULATION AND EVALUATION OF PHYTOSOME LOTION FROM NOTHOPANAX SCUTELLARIUM LEAF EXTRACT FOR HAIR GROWTH
}

\author{
IKA AULIA RAHMI', ABDUL MUN'IM ${ }^{2}$, MAHDI JUFRI ${ }^{3}$
}

${ }^{1}$ Graduate of Herbal Aesthetics, Faculty of Pharmacy, Universitas Indonesia, ${ }^{2}$ Department of Pharmacognosy and Phytochemistry, Faculty of Pharmacy, Universitas Indonesia, ${ }^{3}$ Department of Pharmaceutical Technology and Drug Development, Faculty of Pharmacy, Universitas Indonesia

Email: munim@farmasi.ui.ac.id

Received: 24 May 2021, Revised and Accepted: 16 Sep 2021

\begin{abstract}
Objective: The purpose of this study was to formulate a phytosome lotion from Mangkokan leaf using green solvent extraction.

Methods: Ionic liquid, 1-butyl-3-methylimidazolium tetrafluoroborate, combined with microwave-assisted extraction, was used to obtain flavonoid compounds. Mangkokan leaf extract was formulated into a phytosome with three different ratios of phospholipon (1:0.5), (1:1), and (1:2). Three phytosome formulas were analyzed to identify the best formula. The analysis included morphology, particle size, and zeta potential, entrapment efficiency, and spectrum analysis using an FTIR spectrophotometer. The formula which chosen was formulated into three lotion formulas with different concentration $(20 \% ; 25 \% ; 30 \%)$ then, evaluated for physical stability, and hair growth activity test included hair length, weight, and diameter. Minoxidil and non-phytosome lotion were used as comparison. Data were analyzed using two-way ANOVA.
\end{abstract}

Results: The FTIR of phytosome was confirmed a complex formation of extract and phospholipon. The phytosome morphology was displayed irregular spherical vesicles. Phytosome with the ratio of phospholipon (1:0.5) was formulated into lotion because has a smaller particle size (289 $\mathrm{nm})$, and higher entrapment efficiency $(99.76 \% \pm 0.24)$ than others. Phytosome lotions displayed higher activity than $2 \%$ minoxidil $(\mathrm{p}=0.0001)$ Phytosome lotion (30\%) thus showed the highest efficacy for hair length, weight and diameter.

Conclusion: Mangkokan leaf that extracted using 1-butyl-3-methylimidazolium tetrafluoroborate solvent combined with microwave-assisted extraction then formulated into phytosome lotion has higher activity than $2 \%$ minoxidil. Lotion that contains $30 \%$ mangkokan leaf phytosome was showed the highest efficacy.

Keywords: Flavonoid, Mangkokan leaf, Nothopanax scutellarium, Phytosome, Hair growth activity

(C) 2021 The Authors. Published by Innovare Academic Sciences Pvt Ltd. This is an open access article under the CC BY license (https://creativecommons.org/licenses/by/4.0/) DOI: https://dx.doi.org/10.22159/ijap.2021v13i6.42169. Journal homepage: https://innovareacademics.in/journals/index.php/ijap

\section{INTRODUCTION}

Hair loss is a common complaint in clinical dermatology that occurs in adults [1]. Hair loss occurs worldwide both in men and women, and its prevalence increases with age $[2,3]$. In the United States, more than 21 million women experience Female Pattern Hair Loss (FPHL) [3]. Another study states that there are 1390 men aged 40$69 \mathrm{y}$ was found that the prevalence of full baldness increased with age from 31\% (age 40-55 y) to 53\% (age 65-69 y) [2].

Minoxidil is commonly used for hair loss treatment. Topical minoxidil treatment is considered safe but has some side effects. The most common side effects are irritant contact dermatitis, which has symptoms of itching and thicken the skin. [4). Cases are reported that using topical minoxidil in patients with coronary artery disease may carry a risk for significant systemic cardiovascular symptoms [5, 6].

Herbal therapy has increased in popularity in the last two decades among patients looking for alternatives to conventional medicine. In Indonesia, Mangkokan (Nothopanax scutellarium Merr.) leaf is empirically known to treat hair loss. Leaf extract has known to have hair growth promoter activity in published work, but its mechanism is still unclear. Currently, flavonoids are thought to be active constituents [7-9]. Flavonoid was also known for antioxidant, antimicrobial, and anti-inflammatory [10-12]. Based on a previous study, mangkokan leaf was extracted by ionic liquid microwaveassisted extraction method using 1-butyl-3-methylimidazolium

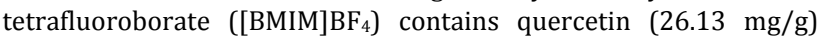
[13]. This method has great advantages for extracting plants with high extraction levels and short extraction times [14-17].

Some hydrophilic flavonoids have poor absorption because of their affinity for the water phase. Poor lipid solubility limits permeability through lipid-rich biological membranes. Besides, flavonoids are large molecules with several phenolic rings that also limit absorption via simple diffusion [18-20]. Water-soluble flavonoids can be converted into nanoscale molecular complexes, called phytosomes that are compatible with lipids [21]. The bioavailability of flavonoids can be increased using this nanoparticle technology. Nanoparticles crossed the membrane barriers efficiently [22].

The use of phytosomes is very beneficial in herbal medicine. These are including drug delivery at the target site of drug action, minimizing toxic effects, drug distribution can be controlled by inserting the drug in the carrier system or changing the structure of the drug at the molecular level. Furthermore, it is also increasing the bioavailability of drugs $[23,24]$.

Flavonoids of herbal extracts lend themselves quite well for the direct binding to phosphatidylcholine [25]. Previous studies have developed a flavonoid such as quercetin phospholipid phagosomal complex. The result was shown that the formulation has better therapeutic efficacy than the molecule in rat liver injury induced by carbon tetrachloride. The phytosomes of curcumin (flavonoid from turmeric, Curcuma longa) and naringenin (flavonoid from grapefruit, Vitis vinifera) were developed in two different studies. Antioxidant activity of the quercetin phospholipid phytosomal complex was significantly higher than pure curcumin in all dose levels tested [26-28]. Quercetin phytosome was produced commercially, Meriva $(500 \mathrm{mg})$ 60VC. This research is never been conducted before which the extract was obtained by an environmentally friendly extraction method to comply with the industry challenges to be more ecological, economical, and innovative. Furthermore, the extract was formulated into phytosome lotion that was known for a successful method to increase its efficacy.

\section{MATERIALS AND METHODS}

\section{Materials}

The material used in this study were mangkokan leaf with specimen number K000792863 from Badan Penelitian Tanaman Rempah dan 
Obat (BALITRO, Bogor, Indonesia), [BMIM] $\mathrm{BF}_{4}$ (Shanghai Cheng Jie Chemical Co. LTD, Shanghai, China), sodium chloride (Merck, Darmstadt, Germany), ethyl acetate (Bratachem, Jakarta, Indonesia), aqua pro injection (PT. Ikapharmindo Putramas, Jakarta, Indonesia), phospholipon 90 G (Sigma, New York, USA) dichloromethane (Merck, Darmstadt, Germany). Dimethicone, olive oil, petrolatum, cetyl alcohol, stearic acid, butylated hydroxyl toluene, triethanolamine, glycerin, and minoxidil were from CV. Cipta Anugrah Bakti Mandiri, Banyuwangi, Indonesia. Methylparaben, and propylparaben were from PT. Brataco Chemical, Cirebon, Indonesia.

The equipment used in this study included a modena Microwave 900 Watt (Buono-MV3002), HPLC (Shimadzu, Kyoto, Japan), C18 bonded-silica gel column ( $5 \mu \mathrm{m}, 150 \times 4.6 \mathrm{~mm}$, GL Sciences, Tokyo, Japan), microwave (Modena MV-320, Jakarta, Indonesia), glass beads (Merck, Darmstadt, Germany), UV-Vis spectrophotometer (Shimadzu, Kyoto, Japan), viscometer Brookfield (Ametek, New York, USA), pH meter (Eutech, Delhi, India), ultrasonicator (Branson, Danbury, USA), rotary vacuum evaporator (Buchi, Flawil, Swiss), Transmission Electron Microscope (JOEL, Peabody, USA), FTIR spectrophotometer (Shimadzu, Kyoto, Japan).

\section{Methods}

\section{Mangkokan leaf extraction}

The dried mangkokan leaves were placed in a boiling flask and

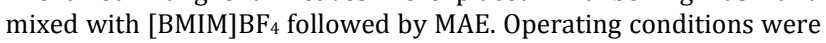

a running time of $10 \mathrm{~min}$, IL concentration of $1.5 \mathrm{~mol}, 10 \mathrm{ml} / \mathrm{g}$ ratios, and power of $10 \mathrm{~W}$. The extracts were filtered using filter paper.

\section{Separation of ionic liquid}

The extract was separated from the ionic liquid by reverse liquidliquid extraction. The extract was added to ethyl acetate $(1: 1)$ in a separatory funnel. The mixture was shaken until two phases formed. The top phase, ethyl acetate, contained the flavonoids, and the bottom phase the ionic liquid. The ionic liquid was re-extracted twice more with ethyl acetate. Ethyl acetate extracts were combined and evaporated to dryness in a water bath.

\section{Phytosome formulation containing mangkokan leaf extract}

The phytosome complex was formulated by mixing phospholipon, and mangkokan leaf extract in three ratios (table 1). Mangkokan leaf extract and phospholipon were dissolved in dichloromethane in a $50 \mathrm{ml}$ round bottom flask and sonicated at $40{ }^{\circ} \mathrm{C}$ for $30 \mathrm{~min}$. The mixture was refluxed for $2 \mathrm{~h}$ at $40^{\circ} \mathrm{C}$ using a rotary vacuum evaporator equipped with a vacuum pump to obtain thin film formation of the leaf extract and phospholipon leaf complex. The speed of the rotary evaporator was gradually increased from 25 to $150 \mathrm{rpm}$. Nitrogen gas was introduced over the thin layer, and the layer was stored in the refrigerator for up to $24 \mathrm{~h}$. After storage, the thin layer was hydrated in phosphate buffer at $\mathrm{pH} 5.5$ at $40{ }^{\circ} \mathrm{C}$. The phytosome suspension formed and was sonicated.

Table 1: Phytosome formulation containing mangkokan leaf extract

\begin{tabular}{llll}
\hline Composition & Ratio & & \\
\cline { 2 - 4 } & F1 (1:0.5) & F2 (1:1) & F3 (1:2) \\
\hline Mangkokan leaf extract (g) & 1 & 1 & 1 \\
Phospholipon 90 G (g) & 0.5 & 1 & 2 \\
\hline
\end{tabular}

\section{Phytosome evaluation}

\section{Phytosome morphology}

Phytosome vesicles were observed using TEM. Samples were dropped on carbon-coated copper grids, dried at room temperature, and stained with phosphotungstic acid. Grids were left for $30 \mathrm{~min}$ before viewing. Results were documented as previously described [29].

\section{Distribution of particle size, zeta potential and polydispersity} index (PDI)

Particle size and zeta potential were analyzed using a Malvern Zetasizer Nano Z computerized system at a scattering angle of $90^{\circ}$ at $25{ }^{\circ} \mathrm{C}$. Before measurement, flavonosomes were diluted with phosphate buffer, and each sample was measured three times [30,31].

\section{FTIR analysis}

FTIR spectra were obtained using an FTIR spectrometer. Samples were mixed with $\mathrm{KBr}$ dry crystals in a ratio of $1: 100$. IR spectra of phospholipon $90 \mathrm{G}$, pure mangkokan leaf extract, and phytosomes were analyzed.

\section{Phytosome entrapment efficiency}

Entrapment efficiency used an indirect method as previously described [31]. The solution of phytosome was analyzed using HPLC under condition was performed in the isocratic mode using a C18 bonded-silica gel column $(5 \mu \mathrm{m}, 150 \times 4.6 \mathrm{~mm})$, and an LC-20AT HPLC system equipped with a UV-Vis detector (SPD-20A). The mobile phase was methanol: aqua pro injection: glacial acetic acid (65:34:1). The UV detector wavelength was $370 \mathrm{~nm}$. The flow rate was $1 \mathrm{ml} / \mathrm{min}$, the run time was $10 \mathrm{~min}$, and the injection volume was $20 \mu \mathrm{l}$ to determine the total content of quercetin, and unentrapped quercetin. The total of quercetin solution was prepared by adding $1 \mathrm{ml}$ of phytosome suspension with $1 \mathrm{ml}$ of methanol. The mixture was homogenized using vortex for $30 \mathrm{sec}$, then sonicated for
$10 \mathrm{~min}$. The unentrapped quercetin was prepared by adding $1 \mathrm{ml}$ of phytosome suspension with $1 \mathrm{ml}$ of methanol. The mixture was homogenized using vortex for $30 \mathrm{sec}$, then centrifuged at $3000 \mathrm{rpm}$ for $60 \mathrm{~min}$. The supernatant was collected. The entrapment efficiency (EE) was then calculated as:

$$
\mathrm{EE}=\frac{\text { total quercetin }- \text { unentrapped quercetin }}{\text { total quercetin }} \times 100 \% \ldots . \text { (Eq. 1) }
$$

\section{Hair growth promoter lotion formulation}

The phytosome lotion formulation was a type o/w preparation with HLB 10. Formulas were divided into lotion base, non-phytosome lotion, and phytosome lotions with three different phytosome concentrations (table 2). The oil phase, including olive oil, dimethicone, petrolatum, stearic acid, cetyl alcohol, propylparaben, was prepared by melting the waxes at $70{ }^{\circ} \mathrm{C}$ and mixing the ingredients uniformly. Then, butylated hydroxyl toluene was added. The aqueous phase, including triethanolamine, methylparaben, glycerin dissolved in distilled water, was prepared by dissolving the water-soluble ingredients. The water phase was heated to $70{ }^{\circ} \mathrm{C}$ until all ingredients were dissolved. When the water and oil phase was at the same temperature, the oil phase was slowly added to the water phase using a homogenizer. The phytosome complex was added gradually when the emulsion had formed. Furthermore, the mixture was stirred for $15 \mathrm{~min}$ using a speed of $18,000 \mathrm{rpm}$ until the formulation became uniform homogenization.

\section{Physical evaluation of hair growth promoter lotion preparation of mangkokan leaf extract}

The prepared formulations were evaluated for $\mathrm{pH}$, organoleptic properties (color, texture, odor), viscosity, and centrifugation. $\mathrm{pH}$ measurement used a $\mathrm{pH}$ meter. Organoleptic characteristics were evaluated through visual observation. The viscosity measurements were performed using a Brookfield viscometer and number 4 spindle. The formulas were centrifuged at $25^{\circ} \mathrm{C}$ at a speed of 3500 rpm for $30 \mathrm{~min}$. 
Table 2: Hair growth promoter lotion formulation

\begin{tabular}{|c|c|c|c|c|c|}
\hline Composition & Base (g) & Non-phytosome formula (g) & Formula 1 (g) & Formula 2 (g) & Formula 3 (g) \\
\hline Phytosome complex & - & 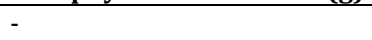 & 20 & 25 & 30 \\
\hline Mangkokan leaf extract & - & 20 & - & - & - \\
\hline Dimethicone & 3 & 3 & 3 & 3 & 3 \\
\hline Olive oil & 1.5 & 1.5 & 1.5 & 1.5 & 1.5 \\
\hline Petrolatum & 1 & 1 & 1 & 1 & 1 \\
\hline Cetyl alcohol & 2 & 2 & 2 & 2 & 2 \\
\hline Stearate acid & 3 & 3 & 3 & 3 & 3 \\
\hline Butylated hydroxyl toluene & 0.02 & 0.02 & 0.02 & 0.02 & 0.02 \\
\hline Triethanolamine & 1.2 & 1.2 & 1.2 & 1.2 & 1.2 \\
\hline Glycerin & 2 & 2 & 2 & 2 & 2 \\
\hline Methylparaben & 0.2 & 0.2 & 0.2 & 0.2 & 0.2 \\
\hline Prophylparaben & 0.1 & 0.1 & 0.1 & 0.1 & 0.1 \\
\hline Distilled water ad until & 100 & 100 & 100 & 100 & 100 \\
\hline
\end{tabular}

\section{Hair growth activity test}

This study used healthy, adult, male New Zealand rabbits, 4-5 mo old, and weighing $1.5 \mathrm{~kg}-2 \mathrm{~kg}$ from the Faculty of Veterinary, Bogor Agriculture Institute Laboratory Animal Center (UPHL, IPB University, Indonesia). The number of tested animals was four rabbits which were determined by Federer's formula. During acclimatization and treatment, the animals were individually caged in a room with a natural light cycle and a temperature range of $25^{\circ} \mathrm{C}-30{ }^{\circ} \mathrm{C}$. Animals had access to food and water ad libitum [31]. All methods for sacrificing animals were approved by the Ethics Committee from Cipto Mangunkusumo Hospital, Faculty of Medicine, Universitas Indonesia.

The rabbits' back was divided into six areas, each of which measured $2 \mathrm{~cm} \times 2 \mathrm{~cm}$ [31]. The rabbits' fur was shaved short using a shaver. These areas are then marked as illustrated below:

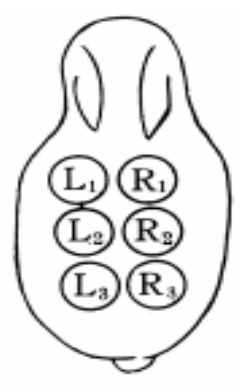

Fig. 1: Study treatment [31]

$\mathrm{L} 1$ is a basic lotion formula area test which is as normal control, $\mathrm{L} 2$ is $2 \%$ minoxidil as the positive control, L3 is non-phytosome lotion formula as the negative control, R1 is test control of phytosome formula 1, R2 is test control of phytosome formula 2, R3 is test control of phytosome formula 3 .

After shaving, backs were smeared with depilatory cream for $5 \mathrm{~min}$. The cream was then rinsed off with water. Ethanol (70\%) was applied to the test areas as an antiseptic. The rabbits were left for 24 $\mathrm{h}$ before use. Each back area was administered a different treatment. Each treatment preparation $(0.5 \mathrm{mg})$ was applied twice a day. The first day of treatment was considered day 0 [8]. The treatment was continued and monitored for four weeks. Observations of hair growth were recorded at weekly intervals. The three longest strands of rabbit fur were pulled out in each of the test areas and measured using calipers. Further, at week four, the weight of the rabbit was determined by pulling out and weighing the fur in each test area. Fur diameter was observed at week three using the SEM [9].

\section{Statistical analysis}

The statistical analysis used Graphpad Prism 8.30 software. Data were analyzed using the Shapiro-Wilk normality test and two-way ANOVA to determine statistical significance $(p<0.05)$ of the differences in means among experimental and control groups.

\section{RESULTS}

\section{Phythosome formulation}

Particle size, zeta potential, and polydispersity index (PDI)

Three phytosome formulas were obtained from different particle sizes. Phytosomes with a combination of mangkokan leaf extract and phospholipon in a ratio of 1: 0.5 show size of $289 \mathrm{~nm}$. A 1:1 ratio shows $470 \mathrm{~nm}$, and a 1:2 ratio shows $545 \mathrm{~nm}$. The results show $p<0,0001$. The phytosome formula with a 1:0.5 ratio shows the best homogeneity. The particle size, zeta potential, and polydispersity index results are listed in table 3.

Table 3: Particle size of phytosomes

\begin{tabular}{|c|c|c|c|}
\hline Formula & Particle size $(\mathrm{nm}) \pm \operatorname{SD}(\mathrm{n}=3)$ & Zeta potential $(\mathrm{mV}) \pm \operatorname{SD}(\mathrm{n}=3)$ & PDI \pm SD (n=3) \\
\hline Phytosome (1:0.5) & $289 \pm 1.41$ & $-9.10 \pm 1.56$ & $0.32 \pm 0.03$ \\
\hline Phytosome (1:1) & $470 \pm 3.98$ & $-8.23 \pm 0.55$ & $0.60 \pm 0.05$ \\
\hline Phytosome $(1: 2)$ & $545 \pm 2.89$ & $-12.3 \pm 0.08$ & $0.47 \pm 0.07$ \\
\hline
\end{tabular}

Note: Note: This test was conducted with three replication. The result shows the means and standard deviation of particle size, zeta potential, and polydispersity index (PDI). The particle size of phytosome (1:0.5) was $289 \pm 1.41$, phytosome (1:1) was $470 \pm 3.98$, and phytosome $(1: 2)$ was $545 \pm 2.89$. The zeta potential of phytosome (1:0.5) was-9.10 \pm 1.56 , phytosome $(1: 1)$ was $470 \pm 3.98$, and phytosome $(1: 2)$ was $545 \pm 2.89$. The polydispersity index of phytosome $(1: 0.5)$ was $0.32 \pm 0.03$, phytosome $(1: 1)$ was $0.60 \pm 0.05$, and phytosome $(1: 2)$ was $0.47 \pm 0.07$.

\section{Entrapment efficiency}

The entrapment efficiency for the three formula ratios were: 1:0.5, $99.76 \% \pm 0.24,1: 1,96.96 \% \pm 0.02$, and $1: 2,96.40 \% \pm 0.45$. The data obtained were processed for normality. The data is normally distributed with significant data $p=0.19(p>0.05)$. Then, it analyzed by one-way ANOVA. The results show $p<0,0001$. Phytosomes with a ratio of mangkokan leaf extract to phospholipon of 1:0.5 showed the highest entrapment. Increasing phospholipon concentration decreased entrapment efficiency. 

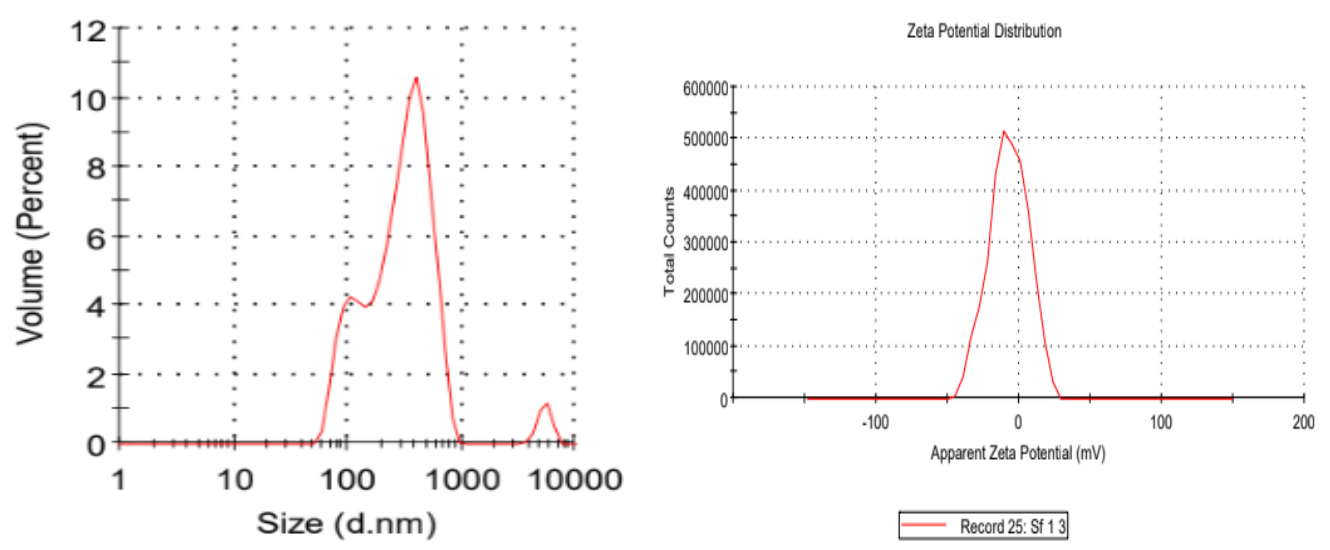

Fig. 2: Particle size and zeta potential curve of phytosome (1:0.5)

\section{Phytosome morphology}

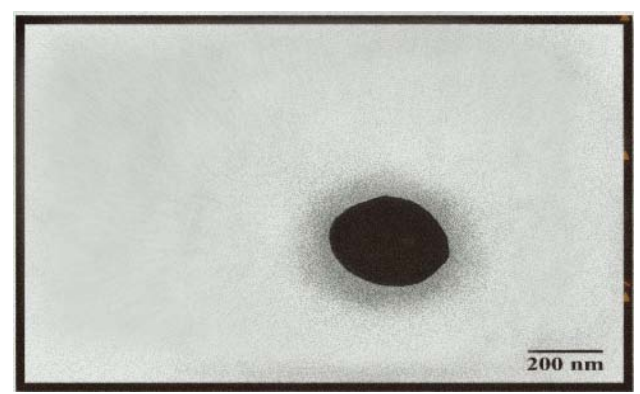

Fig. 3: Phytosome morphology using Transmission Electron Microscope (TEM) with a magnification of $30,000 x$ for phytosome formula with 1:0.5 ratio (F1)

Phytosome morphological analysis using Transmission Electron Microscope (TEM) displayed irregular spherical vesicles measuring $200 \mathrm{~nm}$ (fig. 3) for phytosomes with the 1:0.5 ratio.

\section{Fourier transform infrared spectroscopy analysis}

The infrared spectroscopic analysis confirmed a complex formation by comparing complex spectra with single components and physical mixtures. In FTIR spectra, phospholipon was characterized by peaks at around $3500 \mathrm{~cm}^{-1}$ (hydroxyl stretching), $2900 \mathrm{~cm}^{-1}$ (CH stretching in fatty acid residues), $1700 \mathrm{~cm}^{-1}$ (carbonyl stretching of fatty acid esters), $1200 \mathrm{~cm}^{-1}$ (P=0 stretching), $1100 \mathrm{~cm}^{-1}$ (POC stretching), and $970 \mathrm{~cm}^{-1}$ (N-(CH3) 3 stretching). Flavonoids had hydroxyl group spectra where $\mathrm{O}-\mathrm{H}$ stretching appeared as a sharp peak in the range of $3800-3200 \mathrm{~cm}^{-1}$. In spectra of the three phytosomes, weak physical interactions occurred between hydroxyl or amines free of natural components and polar phospholipid groups during complex formation.

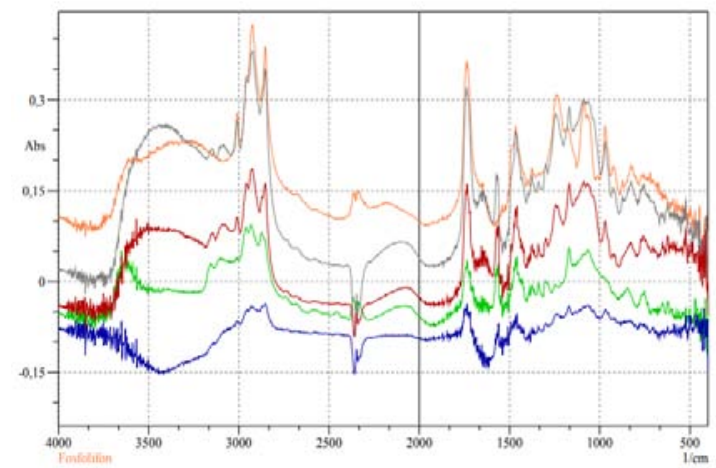

Fig. 4: FTIR spectrum analysis. (Orange: phospholipon $90 \mathrm{G}$, Grey: mangkokan leaf extract, Red: phytosome (1:2), Green: phytosome (1:1), Blue $(1: 0,5)$

Physical evaluation of phytosome lotion of mangkokan leaf extract for hair growth

Organoleptic characteristics and $\mathrm{pH}$ test

Table 4: Organoleptic characteristics of phytosome lotion formulation

\begin{tabular}{|c|c|c|c|c|}
\hline Formula & $\mathrm{pH} \pm \mathrm{SD}(\mathrm{n}=3)$ & Color & Odor & Texture \\
\hline Phytosome Lotion Formula 1 & $7.59 \pm 0.03$ & Green & Characteristic & Soft, easy to absorb, not greasy \\
\hline Phytosome Lotion Formula 2 & $7.48 \pm 0.03$ & Green & Characteristic & Soft, easy to absorb, not greasy \\
\hline Phytosome Lotion Formula 3 & $7.11 \pm 0.13$ & Green & Characteristic & Soft, easy to absorb, not greasy \\
\hline
\end{tabular}

Note: This test was conducted with three replication. The result of the $\mathrm{pH}$ test in table 4. shows the means and standard deviations. Based on the observation result, the $\mathrm{pH}$ value of phytosome lotion formula 1 was 7 . $59 \pm 0.03$, phytosome lotion formula 2 was $7.48 \pm 0.03$, and phytosome lotion formula 3 was $7.11 \pm 0.13$. All lotions have a green color, mangkokan leaf characteristic odor, and soft, easy to absorb, not greasy textures.

Organoleptic characteristics and $\mathrm{pH}$ are provided in table 4. $\mathrm{pH}$ ranged from 7.11 to 7.59. Phytosome lotion formulas show $\mathrm{pH}$ values compatible with the skin, and test animals did not display irritation.

\section{Viscosity test}

Table 5: Phytosome lotion viscosity

\begin{tabular}{ll}
\hline Formula & Viscosity (cps) \pm SD $(\mathbf{n}=\mathbf{3})$ \\
\hline Phytosome Lotion Formula 1 & $1680 \pm 20$ \\
Phytosome Lotion Formula 2 & $1880 \pm 40$ \\
Phytosome Lotion Formula 3 & $2200 \pm 20$ \\
\hline
\end{tabular}

Note: This test was conducted with three replication. The result shows the means and standard deviation of viscosity value. The 
viscosity value of phytosome lotion formula 1 was $1680 \pm 20$, phytosome lotion formula 2 was $1880 \pm 40$, and phytosome lotion formula 3 was $2200 \pm 20$.

Viscosity increased along with phytosome concentration in the lotion formula (table 5).

\section{Centrifugation test}

When phytosome lotions were centrifuged at $3500 \mathrm{rpm}$ for $30 \mathrm{~min}$, no separation was observed, and lotions displayed good stability.

\section{Hair growth activity evaluation \\ Hair length}

Rabbit's hair length was observed weekly for four weeks. As many as three rabbit hairs were taken in each test area to calculate the average hair length. The rabbit hair lengths are listed in table 6 . The data obtained were processed using two-way ANOVA. The results of the data analysis, it shows that the data is normally distributed with significant data $\mathrm{p}=0.06(\mathrm{p}>0.05)$.

From the test results, it is known that hair growth increases every week. Statistical data shows p-value $<0.01$ on minoxidil control, which means that there is a significant difference to phytosome lotion formula 3 , while phytosome lotion formula 1 and phytosome lotion formula 2 have a significant difference with $p$-value $<0.05$. The hair growth in phytosome formula 3 was the highest compared to other formulas.

Data were examined for normality with the Shapiro-Wilk test. The results show significance values of $p<0.05$, indicating that data are normally distributed. Data were processed using two-way ANOVA. A significant $(p<0.0001)$ increase in hair length was observed each week. The highest hair growth rate was induced by phytosome lotion formula 3 .

Table 6: Average rabbit hair length

\begin{tabular}{|c|c|c|c|c|}
\hline \multirow[t]{2}{*}{ Treatment } & \multicolumn{4}{|c|}{ The average rabbit hair length $(\mathrm{cm}) \pm S D(n=3)$} \\
\hline & Week-1 & Week-2 & Week-3 & Week-4 \\
\hline Normal control & $0.22 \pm 0.05$ & $0.43 \pm 0.03$ & $0.52 \pm 0.02$ & $0.59 \pm 0.03$ \\
\hline Positive control & $0.39 \pm 0.05$ & $0.60 \pm 0.03$ & $0.84 \pm 0.02$ & $1.10 \pm 0.12$ \\
\hline Negative control & $0.33 \pm 0.02$ & $0.61 \pm 0.03$ & $0.85 \pm 0.02$ & $1.10 \pm 0.12$ \\
\hline Phytosome formula 1 & $0.37 \pm 0.02$ & $0.72 \pm 0.01$ & $0.87 \pm 0.03$ & $1.22 \pm 0.21$ \\
\hline Phytosome formula 2 & $0.42 \pm 0.01$ & $0.76 \pm 0.02$ & $0.92 \pm 0.03$ & $1.44 \pm 0.17$ \\
\hline Phytosome formula 3 & $0.40 \pm 0.04$ & $0.80 \pm 0.01$ & $0.97 \pm 0.04$ & $1.72 \pm 0.19$ \\
\hline
\end{tabular}

Note: Normal control is basic lotion formula, positive control is $2 \%$ minoxidil, the negative control is non-phytosome lotion formula, phytosome formula 1 is containing 20-gram phytosome complexes, phytosome formula 2 is containing 25 -gram phytosome complexes, phytosome formula 3 is containing 30 -gram phytosome complexes. Each treatment has conducted with three samplings. The result shows that hair growth increases every week. At the first week, the mean and standard deviation of normal control was $0.22 \pm 0.05$, positive control was $0.39 \pm 0.05$, a negative control was $0.33 \pm 0.02$, phytosome formula 1 was $0.37 \pm 0.02$, phytosome formula 2 was $0.42 \pm 0.01$, and phytosome formula 3 was $0.40 \pm 0.04$. At the second week, the hair length of normal control was $0.43 \pm 0.03$, positive control was $0.60 \pm 0.03$, a negative control was $0.61 \pm 0.03$, phytosome formula 1 was $0.72 \pm 0.01$, phytosome formula 2 was $0.76 \pm 0.02$, and phytosome formula 3 was $0.80 \pm 0.01$. At the third week, the hair length of normal control was $0.52 \pm 0.03$, positive control was $0.84 \pm 0.02$, a negative control was $0.85 \pm 0.02$, phytosome formula 1 was $0.87 \pm 0.03$, phytosome formula 2 was $0.92 \pm 0.03$, and phytosome formula 3 was $0.97 \pm 0.04$. At the fourth week, the hair length of normal control was $0.59 \pm 0.03$, positive control was $1.10 \pm 0.12$, negative control was $1.10 \pm 0.12$, phytosome formula 1 was $1.22 \pm 0.21$, phytosome formula 2 was $1.44 \pm 0.17$, and phytosome formula 3 was $1.72 \pm 0.19$.

\section{Hair weight}

Hair weight was measured at the fourth week for $1 \mathrm{x} 1 \mathrm{~cm}$ test area (table 7).

Table 7: Rabbit hair weight at week 4

\begin{tabular}{ll}
\hline Treatment & Mean $(\mathbf{m g}) \pm$ SD $(\mathbf{n}=\mathbf{3})$ \\
\hline Normal control & $7.87 \pm 0.03$ \\
Positive control & $13.55 \pm 0.08$ \\
Negative control & $13.19 \pm 0.09$ \\
Phytosome Lotion formula 1 & $14.39 \pm 0.10$ \\
Phytosome Lotion formula 2 & $14.56 \pm 0.09$ \\
Phytosome Lotion formula 3 & $14.78 \pm 0.05$ \\
\hline
\end{tabular}

Note: Normal control is basic lotion formula, positive control is $2 \%$ minoxidil, a negative control is non-phytosome lotion formula, phytosome formula 1 is containing 20 gram phytosome complex, phytosome formula 2 is containing 25 gram phytosome complex, phytosome formula 3 is containing 30 gram phytosome complex. Each treatment was conducted with three replication. The result shows that the mean and standard deviation of normal control was $7.87 \pm 0.03$, positive control was $13.55 \pm 0.08$, a negative control was $13.19 \pm 0.09$, phytosome formula 1 was $14.39 \pm 0.10$, phytosome formula 2 was $14.56 \pm 0.09$, and phytosome formula 3 was $14.78 \pm 0.05$.

Data for rabbit hair weight were normally distributed with $\mathrm{p}=0.512$ $(\mathrm{p}>0.05)$, and with $p=0.0001$ for the inter-group test. The test shows a significant result of increased hair weight. This increased hair weight was higher for minoxidil than phytosome lotions. Phytosome lotion formula 3 shows greater weight than formulas 1 and 2 . The latter formulas were equally effective.

\section{Hair diameter}

Hair diameter was measured at week three using a scanning electron microscope (SEM). Phytosome formula 3 induced the largest hair diameter compared to other formulas (table 8).

Table 8: Hair diameter

\begin{tabular}{ll}
\hline Treatment & Mean $(\boldsymbol{\mu m}) \pm$ SD $(\mathbf{n}=\mathbf{3})$ \\
\hline Normal control & $13.238 \pm 1.76$ \\
Positive control & $16,556 \pm 1.86$ \\
Negative control & $15.368 \pm 2.16$ \\
Phytosome formula 1 & $18.552 \pm 3.09$ \\
Phytosome formula 2 & $23.951 \pm 1.74$ \\
Phytosome formula 3 & $24.740 \pm 2.28$ \\
\hline
\end{tabular}

Note: Normal control is basic lotion formula, positive control is $2 \%$ minoxidil, a negative control is non-phytosome lotion formula, phytosome formula 1 is containing 20 -gram phytosome complexes, phytosome formula 2 is containing 25 -gram phytosome complexes, phytosome formula 3 is containing 30 -gram phytosome complexes. Each treatment was conducted with three replication. The result shows that the mean and standard deviation of normal control was $13.238 \pm 1.76$, positive control was $16,556 \pm 1.86$, a negative control was $15.368 \pm 2.16$, phytosome formula 1 was $18.552 \pm 3.09$, phytosome formula 2 was $23.951 \pm 1.74$, and phytosome formula 3 was $24.740 \pm 2.28$. 
SEM was used to assess hair shafts, and visualize the extent of damage if any. Under SEM, hair shafts from formula-treated rabbits appeared smooth, and keratinized squamous epithelium was well arranged (fig. 5).

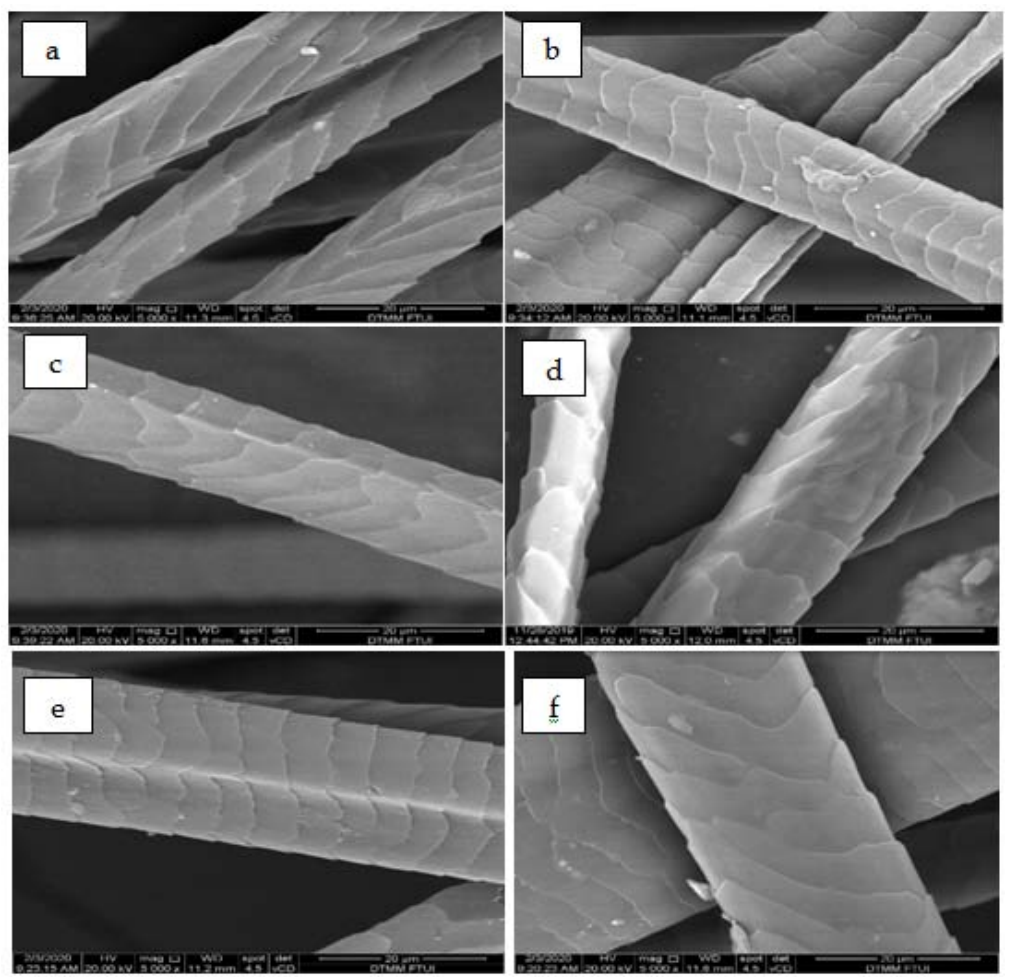

Fig. 5: Scanning electron microscope of hair a) normal group b) negative control c) positive control d) phytosome formula 1 e) phytosome formula $2 \mathrm{f}$ ) phytosome formula 3 using a magnification of $5.000 \mathrm{x}$

\section{DISCUSSION}

Phytosomes are formulated to overcome poor lipid solubility caused by a glucose group on flavonoid molecules. These phytosomes were produced using thin layer hydration because this method is relatively easy to implement and is capable of producing relatively stable vesicles. Some factors may influence the production of phytosome vesicles, such as evaporation time, hydration time, hydration media, and temperature. The rotational speed of the flask influences the thickness and uniformity of the lipid film [32]. After the phytosome was formed, morphology, particle size, zeta potential, polydispersity index, FTIR spectrum, and entrapment efficiency were analyzed.

Phytosome morphological, which was analyzed using TEM was presented with homogeneous, spherical, well nanoparticles. The particle size showed that greater phospholipid content produced larger particle sizes. The high concentration increases the viscosity of the solution and delays the drug diffusion within the polymer droplets. Another study showed that an increase in polymer concentration can increase particle size. It occurred since as polymer concentration increases it produces a significant increase in the viscosity in a fixed volume of solvent, thus leading to an increase of droplet size and finally a higher particle size [33-35].

The zeta potential reflects electrostatic potential, or the repulsive charge, between particles. The more positive or negative this potential, the greater the repulsion forces that tend to reduce particle aggregation. Nanoparticles with zeta potential above $+30 \mathrm{mV}$ and below-30 mV show good suspension stability because surface charge prevents aggregation. Zeta potential values for F1, F2, and F3 indicate that the three formulas may be subject to aggregation.

A PDI test result indicates a homogeneous sample because the PDI of the phytosomes is less than 0.5 to close to zero it means that the sample has low heterogeneity or homogeneous [36]. Phytosome formula 1 displayed the highest homogeneity.
Spectra of the mixture of extract and phospholipon in phytosome form show band intensities were decreased. Entire peaks of both extract and phospholipon were shown at their physical mixture locations indicating no chemical interaction occurred in the physical mixture.

The entrapment efficiency of the phytosomes was carried out to determine the total of quercetin entrap in the phytosome. The phytosome F1 formulation (1:0.5) showed the highest entrapment efficiency used for the lotion formula. The more lipid concentration the decreases the entrapment efficiency. The increase of lipids does not help in entrap more quercetin into the phytosome matrix. The higher the lipid content, make the lipid matrix forms crystals that reduce bond with quercetin. This causes quercetin to leave the matrix. The number of active substances outside the matrix will reduce entrapment efficiency [36].

The phytosome F1 formula (1:0.5) was chosen for the lotion formulation because it has a smaller particle size than other formulas and the highest entrapment efficiency. The phytosome lotion preparations were made into three different formulas of phytosome concentrations. The organoleptic test was carried out of three formulas, including color, aroma, and texture. The difference in levels of color and aroma is due to differences in the number of phytosomes contained in the lotion. The texture of the three formulas is comfortable to use because it is soft, absorbs easily, and is not greasy.

The $\mathrm{pH}$ test was aimed to observe the possibility of a change in $\mathrm{pH}$ during storage which is related to the stability of the active substance, effectiveness, and skin condition. During hair growth activity evaluation, there is no rabbit that had an irritation. A centrifugation test was carried out to determine the stability of the lotion due to the influence of high speed. Three lotion formulas were centrifuged at $3500 \mathrm{rpm}$ for $30 \mathrm{~min}$. There was no separation of lotion formulas. Three lotion formulas are stable. 
The viscosity of the lotion formula shows that the greater the phytosome concentration of the mangkokan leaf extract contained in the lotion, the greater the viscosity. Viscosity can affect comfortability during application. Too high viscosity will reduce comfortability because it will be difficult to flow out from the packaging. Too low viscosity will interfere with the application on the skin because it will be dripping from the skin. The formula with too high or too low viscosity is not comfortable to use [37].

Previous studies were known that quercetin is the main active compound in the mangkokan leaf [7-9]. The result of this study showed increasing lipids content did not help entrap more quercetin into the phytosome matrix. As phospholipid content increased entrapment decreased. Instead, higher lipid content induced crystals in the lipid matrix that reduced bonding with quercetin. Reduced bonding allows quercetin to escape the matrix. The number of active substances outside the matrix also reduces entrapment efficiency [38]. Overall, tests of phytosome formulas indicate that formula 1 is the best candidate for a stable lotion that might promote hair growth.

Hair growth was assessed using length, weight, and diameter measures of rabbit hair. Phytosome lotion induced greater growth than non-phytosome lotion, and phytosome lotion formula 3 had the best activity of all formulas including $2 \%$ minoxidil. The higher the phytosome content in the lotion, the greater the activity of hair growth. Another study showed phytosome formulation exhibited better therapeutic effectiveness [39].

The hair growth test was compared to $2 \%$ minoxidil because minoxidil was widely used as a hair growth promoter. Minoxidil has a mechanism of action as a vasodilator by the opening of potassium channels located on the smooth muscles of the peripheral artery, causing hyperpolarization of the cell membrane [40]. Minoxidil also stimulated prostaglandin E2 production by activating prostaglandinendoperoxide synthase-123 and expression of the prostaglandin E2 receptor was enhanced by minoxidil. It may enable hair follicles to grow continuously and maintain the anagen phase [41, 42]. The hair growth test was also compared with the mangkokan leaf extract lotion formula to observe the effect of hair growth compared to the phytosome lotion formula.

Rabbit hair length increased weekly. This hair growth is not due to the base lotion that showed no effect on hair growth. Phytosome formula 3 displayed the most rapid growth compared with $2 \%$ minoxidil and other formulas. Hair weight was measured with hair from a $1 \times 1 \mathrm{~cm}$ patch in the test area. By four weeks, hair weight was sufficient to measure accurately. Phytosome formulas were roughly equivalent to minoxidil in inducing hair length, but minoxidil was superior in inducing hair mass. Formula 3 was the most effective among phytosome lotions. Phytosome formula 3 displayed the largest hair diameter. Healthy hair shafts were observed using SEM, showing smooth well-arranged cuticles.

The search for natural ingredients that stimulate hair growth continues. Mangkokan leaf contains flavonoids, specifically quercetin. Quercetin reduces HSP70 levels in the skin of alopecia mice induced by heat [43]. The anti-inflammatory properties of quercetin suggest that alopecia aerate may respond to quercetin through inhibition of HSP70 induction. Quercetin, additionally, reduces the regulation of $N F-\kappa B$, which can increase the expression of pro-inflammatory cytokines, such as TNF- $\alpha$ and IL-1 [44]. In addition, quercetin modulates the immune response by suppressing dendritic cells $[45,46]$. Quercetin thus shows the potential to inhibit the breakdown of IP in Androgen Alopecia.

\section{CONCLUSION}

Mangkokan leaf was extracted by ionic liquid microwave-assisted extraction method using [BMIM] $\mathrm{BF}_{4}$. The extract was formulated into phytosomes with different ratios of phospholipon (1:0.5), (1:1), and $(1: 2)$ then analyzed for particle size, zeta potential, polydispersity index, morphological structure, FTIR spectrum and entrapment efficiency. Based on the analysis, the FTIR of phytosome confirmed that phytosome morphology forms a complex formation between extract and phospholipon. Among phytosome with the ratio of phospholipon (1:0.5), phytosome (1:1), and phytosome (1:2) were showed that phytosome $(1: 0.5)$ has the smallest particle size, and the highest entrapment efficiency $(99.76 \% \pm 0.24)$. The best phytosome formula $11: 0.5)$ was chosen to formulate into a lotion with different phytosome contain $20 \mathrm{~g}, 25 \mathrm{~g}$, and $30 \mathrm{~g}$. Hair growth activity evaluation was conducted to basic lotion formula as normal control, $2 \%$ minoxidil as the positive control, mangkokan leaf extract as the negative control, and three different concentration of phytosome. Data were analyzed using two-way ANOVA. The result was showed lotion that contains $30 \mathrm{~g}$ of phytosome has the highest efficacy for hair growth stimulation.

\section{ACKNOWLEDGEMENT}

This research was supported by PUTI Q3 from Directorate Research and Community Engagement Universitas Indonesia No: NKB 1811/UN2.RST/HKP.05.00/2020

\section{FUNDING}

Nil

\section{AUTHORS CONTRIBUTIONS}

All the authors have contributed equally.

\section{CONFLICT OF INTERESTS}

The authors declare no conflicts of interest.

\section{REFERENCES}

1. Alfonso M, Richter-Appelt H, Tosti A, Viera MS, García M. The psychosocial impact of hair loss among men: A multinational European study. Curr Med Res Opin. 2005;21(11):1829-36. doi: 10.1185/030079905X61820, PMID 16307704.

2. Tang PH, Chia HP, Cheong LL, Koh D. A community study of male androgenetic alopecia in Bishan, Singapore. Singapore Med J. 2000;41(5):202-5. PMID 11063167.

3. Leavitt M. Understanding and management of female pattern alopecia. Facial Plast Surg. 2008;24(4):414-27. doi: 10.1055/s0028-1102905, PMID 19034818.

4. Friedman ES, Friedman PM, Cohen DE, Washenik K. Allergic contact dermatitis to topical minoxidil solution: etiology and treatment. J Am Acad Dermatol. 2002;46(2):309-12. doi: $10.1067 /$ mjd.2002.119104, PMID 11807448.

5. Çilingiroglu M, Akkus N, Sethi S, Modi KA. Large pericardial effusion induced by minoxidil. Turk Kardiyol Dern Ars. 2012;40(3):255-8. doi: 10.5543/tkda.2012.63904, PMID 22864322.

6. Karam P. Topical minoxidil therapy for androgenic alopecia in the Middle East. The middle-eastern topical minoxidil study group. Int J Dermatol. 1993;32(10):763-6. doi: 10.1111/j.13654362.1993.tb02756.x, PMID 8225726.

7. Handojo. Stability test and physical activity white rat hair growth gel extracts of preparations Mangkokan (Nothopanax Scutellarium, Merr] [bachelor thesis]. Indonesia: Faculty of Pharmacy, University of Indonesia; 2011.

8. Amelia L. Hair growth promoter activity and safety test of ethosome gel of ethyl acetate fraction of Mangkokan leave (Nothopanax scutellarium, Merr) [magister thesis]. Indonesia: Faculty of Pharmacy, University of Indonesia; 2017.

9. Rifkia V, Jufri M, Mun'im A. Hair growth-promoting activity of Nothopanax scutellarium Merr. Leaves. J Young Pharm. 2017;9(3):436-40. doi: 10.5530/jyp.2017.9.85.

10. Sambandam B, Thiyagarajan D, Ayyaswamy A, Raman P. Extraction and isolation of flavonoid quercetin from the leaves of Trigonella foenum-Graecum and their antioxidant activity. Int J Pharm Pharm Sci. 2016;8:120-4.

11. Hartati R, Suganda AG, Fidrianny I, Ginting TM. Total flavonoid content and antimicrobial properties of four species of Zingiberaceae. Int J Pharm Pharm Sci. 2014;6:142-8.

12. Hossain H Shahid-Ud-Daula A, Jahan I. Evaluation of antinociceptive and antioxidant potential from the leaves of Spilanthes paniculata growing in Bangladesh. Int J Pharm Phytopharmacol Res. 2012;1:178-86.

13. Rahmi IA, Jufri M, Mun'im A. Extraction of quercetin from Nothopanax scutellarium Leaves via ionic liquid-based 
microwave-assisted

extraction.

Pharmacogn 2020;12(6s):1512-7. doi: 10.5530/pj.2020.12.207.

14. Wei Z, Zu Y, Fu Y, Wang W, Luo M, Zhao C, Pan Y. Ionic liquidsbased microwave-assisted extraction of active components from pigeon pea leaves for quantitative analysis. Sep Purif Technol. 2013;102:75-81. doi: 10.1016/j.seppur.2012.09.031.

15. Liu X, Huang $X$, Wang $Y$, Huang $S$, Lin $X$. Design and performance evaluation of ionic liquid-based microwaveassisted simultaneous extraction of kaempferol and quercetin from Chinese medicinal plants. Anal Methods. 2013;5(10):2591-601. doi: 10.1039/c3ay40202a.

16. Zhang Q, Zhao SH, Chen J, Zhang LW. Application of ionic liquidbased microwave-assisted extraction of flavonoids from Scutellaria baicalensis Georgi. J Chromatogr B Analyt Technol Biomed Life Sci. 2015;1002:411-7. doi: 10.1016/j.jchromb.2015.08.021, PMID 26367465.

17. Arrahman A, Syahdi RR, Permatasari H, Sari IFP, Mun'im A Efficacy of ionic liquid [MIM]Br-based MAE on resveratrol and phenolic compounds extraction from Gnetum gnemon seed and their DPP-4 inhibitory activity. Int J Appl Pharm. 2018;10 Special Issue 1:168-71. doi: http://dx.doi.org/ 10.22159/ ijap.2018.v10s1.36.

18. Paleco R, Vucen SR, Crean AM, Moore A, Scalia S. Enhancement of the in vitro penetration of quercetin through pig skin by combined microneedles and lipid microparticles. Int J Pharm. 2014;472(1-2):206-13. doi: 10.1016/j.ijpharm.2014.06.010, PMID 24928134.

19. Pyo SM, Meinke M, Keck CM, Muller RH. Rutin- increased antioxidant activity and skin penetration by nanocrystal technology (smartCrystals). Cosmetics. 2016;3(1):9. doi: 10.3390/cosmetics3010009.

20. Ghanbarzadeh B, Babazadeh A, Hamishehkar H. Nanophytosome as a potential food-grade delivery system. Food Biosci. 2016;15:126-35. doi: 10.1016/j.fbio.2016.07.006.

21. Rajendra A, Giriraj TK, Vivek KP. Phytosome: an approach to increase the bioavailability of plant extract. Int J Pharm Pharm Sci. 2011;3(2):1-3.

22. Pandey R, Ahmad Z, Sharma S, Khuller GK. Nano-encapsulation of azole antifungals: potential applications to improve oral drug delivery. International Journal of Pharmaceutics. 2005;301(12):268-76. doi: 10.1016/j.ijpharm.2005.05.027.

23. Awasthi R, Kulkarni GT, Pawar VK. Phytosome: an approach to increase the bioavailability of plant extract, International Journal of Pharmacy and Pharmaceutical Sciences. Int J Pharm Pharm Sci. 2011;3(2)1-3.

24. Shivam S. Development and in vitro evaluation of phytosome of terbinafine hydrochloride for oral drug delivery. Int J App Pharm. 2020;12(5):85-94. doi: https://doi.org/10.22159/ ijap.2020v12i5.38220

25. Sharma S, Phytosome SM. A review. Planta Ind. 2005;1.

26. Maiti K, Mukherjee K, Gantait A, Ahamed HN, Saha BP, Mukherjee PK. Enhanced therapeutic benefit of a quercetinphospholipid complex in carbon tetrachloride-induced acute liver injury in rats: A comparative study. Iran J Pharmacol Ther. 2005;4.

27. Maiti K, Mukherjee K, Gantait A, Saha BP, Mukherjee PK. Curcumin-phospholipid complex: Preparation, therapeutic evaluation and pharmacokinetic study in rats. Int J Pharm 2007;330(1-2):155-63. doi: 10.1016/j.ijpharm.2006.09.025, PMID 17112692.

28. Maiti K, Mukherjee K, Gantait A, Saha BP, Mukherjee PK. Enhanced therapeutic potential of a naringenin-phospholipid complex in rats. J Pharm Pharmacol. 2006;58(9):1227-33. doi 10.1211/jpp.58.9.0009, PMID 16945181.

29. Surini S, Mubarak H, Ramadon D. Cosmetic serum-containing grape (Vitis vinifera L.) seed extract phytosome: formulation and in vitro penetration study. J Young Pharm. 2018;10(2s):S51-5. doi: 10.5530/jyp.2018.2s.10.
30. Karthivashan G, Masarudin MJ, Kura AU, Abas F, Fakurazi S. Optimization, formulation, and characterization of multiflavonoids-loaded Flavanosome by bulk or sequential technique. Int J Nanomedicine. 2016;11:3417-34. doi: 10.2147/IJN.S112045, PMID 27555765.

31. Kanedi M, Lande ML, Nurcahyani N, Anggraeni IR, Yulianty. Hair-growth promoting activity of plant extracts of suruhan (Peperomia pellucida) in rabbits. Int J Pharm Biol. 2017;12:18 23. Doi:10.9790/3008-1205061823.

32. Venema FR, Weringa WD. The interactions of phospholipid vesicles with some anti-inflammatory agents. J Colloid Interface Sci. 1988;125(2):484-92. doi: 10.1016/0021-9797(88)90013-6.

33. Bodmeier R, McGinity JW. Solvent selection in the preparation of poly(dl-lactide) microspheres prepared by the solvent evaporation method. International Journal of Pharmaceutics. 1988;43(1-2):179-86. doi: 10.1016/0378-5173(88)90073-7.

34. Fu X, Ping Q, Gao Y. Effects of formulation factors on encapsulation efficiency and release behaviour in vitro of huperzine A-PLGA microspheres. J Microencapsul. 2005;22:705-14.

35. Soni ML, Kumar M, Namdeo KP. Sodium alginate microspheres for extending drug release: formulation and in vitro evaluation. Int J Drug Delivery. 2010;2(1):64-8. doi: 10.5138/ijdd.2010.0975.0215.02013.

36. Malvern: Zetasizer Nano User. Manual. United Kingdom: Malvern; 2013.

37. Martin A, Swarbick J, Cammarata A. Farmasi Fisik: Ddasardasar Farmasi Fisik dalam Ilmu Farmasetika. Jakarta: Universitas Indonesia; 2008.

38. Sun R, Zhao G, Ni S, Xia Q. Lipid based nanocarriers with different lipid compositions for topical delivery of resveratrol: comparative analysis of characteristics and performance. J Drug Deliv Sci Technol. 2014;24(6):591-600. doi: 10.1016/S1773-2247(14)50124-4.

39. Sharma S, Sahu AN. Development, characterization, and evaluation of hepatoprotective effect of Abutilon indicum and Piper longum Phytosomes. Pharmacognosy Res. 2016;8(1):2936. doi: 10.4103/0974-8490.171102, PMID 26941533.

40. Messenger AG, Rundegren J. Minoxidil: mechanisms of action on hair growth. $\mathrm{Br}$ J Dermatol. 2004;150(2):186-94. doi: 10.1111/j.1365-2133.2004.05785.x, PMID 14996087.

41. Michelet JF, Commo S, Billoni N, Maheé YF, Bernard BA. Activation of cytoprotective prostaglandin Synthase-1 by minoxidil as A possible explanation for its hair growthstimulating effect. J Invest Dermatol. 1997;108(2):205-9. doi: 10.1111/1523-1747.ep12334249, PMID 9008235.

42. Shin H, Kwack MH, Shin SH, Oh JW, Kang BM, Kim AA, Kim J, Kim MK, Kim JC, Sung YK. Identification of transcriptional targets of Wnt/beta-catenin signaling in dermal papilla cells of human scalp hair follicles: EP2 is a novel transcriptional target of Wnt3a. J Dermatol Sci. 2010;58(2):91-6. doi: 10.1016/j.jdermsci.2010.02.011, PMID 20347274.

43. Wikramanayake TC, Villasante AC, Mauro LM, Perez CI, Schachner LA, Jimenez JJ. Prevention and treatment of alopecia areata with quercetin in the $\mathrm{C} 3 \mathrm{H} / \mathrm{HeJ}$ mouse model. Cell Stress Chaperones. 2012;17(2):267-74. doi: 10.1007/s12192-0110305-3, PMID 22042611.

44. Nam NH. Naturally occurring NF-kappaB inhibitors. Mini- Rev Med Chem. 2006;6(8):945-51. doi: 10.2174/ 138955706777934937 , PMID 16918500.

45. Huang RY, Yu YL, Cheng WC, Ou Yang CN, Fu E, Chu CL Immunosuppressive effect of quercetin on dendritic cell activation and function. J Immunol. 2010;184(12):6815-21. doi: 10.4049/jimmunol.0903991, PMID 20483746.

46. Nickel T, Hanssen H, Sisic Z, Pfeiler S, Summo C, Schmauss D, Hoster E, Weis M. Immunoregulatory effects of the flavonol quercetin in vitro and in vivo. Eur J Nutr. 2011;50(3):163-72. doi: 10.1007/s00394-010-0125-8, PMID 20652710 